\title{
Drug Resistance Pattern in Pulmonary Tuberculosis Patients and Risk Factors Associated with Multi-Drug Resistant Tuberculosis
}

\author{
S. Maharjan1*, A. Singh1, D. K. Khadka², M. Aryal1 \\ ${ }^{1}$ Central Department of Microbiology, Tribhuvan University, Kirtipur, Nepal \\ ${ }^{2}$ National Tuberculosis Center, Thimi, Nepal \\ Email: *maharjansajina92@yahoo.com
}

How to cite this paper: Maharjan, S., Singh, A., Khadka, D.K. and Aryal, M. (2017) Drug Resistance Pattern in Pulmonary Tuberculosis Patients and Risk Factors Associated with Multi-Drug Resistant Tuberculosis. Journal of Tuberculosis Research, 5, 106-117.

https://doi.org/10.4236/jtr.2017.52012

Received: December 14, 2016

Accepted: June 13, 2017

Published: June 19, 2017

Copyright $\odot 2017$ by authors and Scientific Research Publishing Inc. This work is licensed under the Creative Commons Attribution International License (CC BY 4.0).

http://creativecommons.org/licenses/by/4.0/

\begin{abstract}
Introduction: Anti-tuberculosis drug resistance is a major problem in tuberculosis (TB) control programme, particularly multi-drug resistance TB (MDR-TB) in Nepal. Drug resistance is difficult to treat due to its associated cost and side effects. The objective of this study was to assess the drug resistance pattern and assess risk factor associated with MDR-TB among pulmonary tuberculosis patients attending National Tuberculosis Center. Methodology: The comparative cross sectional study was conducted at National Tuberculosis Center during August 2015 to February 2015. Early morning sputum samples were collected from pulmonary tuberculosis suspected patients and subjected to Ziehl-Neelsen staining and fluorochrome staining and culture on Lowenstein-Jensen (LJ) medium. Drug Susceptibility test was performed on culture positive isolates by using proportion method. Univariate and multivariate analysis was computed to assess the risk factors of MDR-TB. Results: Out of 223 sputum samples, 105 were fluorochrome staining positive, 85 were $\mathrm{ZN}$ staining positive and 102 were culture positive. Out of 102 culture positive isolates, $37.2 \%$ were resistance to any four anti-TB drugs. 11 (28.9\%) were initial drug resistance and 28 (43.7\%) were acquired drug resistance. The overall prevalence of MDR-TB was $11.7 \%$, of which 2 (5.3\%) were initial MDR-TB and 10 (15.6\%) were acquired MDR-TB. Univariate and multivariate analysis showed female were significantly associated $(P=0.05)$ with MDR-TB. Conclusion: Drug resistance TB particularly MDR-TB is high. The most common resistance pattern observed in this study was resistance to both isoniazid and rifampicin. Female were found to be associated with MDR-TB. Thus, early diagnosis of TB and provision of culture and DST are crucial in order to combat the threat of DR-TB.
\end{abstract}




\section{Keywords}

Tuberculosis, Pulmonary Tuberculosis, Anti-Tuberculosis Drug Resistance, MDR-TB

\section{Introduction}

Tuberculosis (TB) is an important public health problem responsible for deaths worldwide [1]. It is the second leading cause of death due to single infectious agent first being HIV/AIDS [2]. TB ranks as sixth leading cause of death among other 20 causes of death in Nepal [3]. Every year over 80,000 people developed TB in Nepal [3]. Nearly 20,000 cases are infectious sputum positive TB and about 45,000 are all forms of new TB [3]. Although treatment by Directly Observed Short course (DOTS) has reduced the number of deaths, $5000-7000$ people are still dying per year by TB [4].

The emergence of Multi-drug resistance TB (MDR-TB) and extensively drug resistance TB (XDR-TB) pose challenge in TB control programme [5]. The frequency of MDR-TB is $2.2 \%$ among new cases and $15.4 \%$ among retreatment cases in Nepal and 8\% of MDR-TB had XDR-TB [3]. MDR-TB occurs when organisms show resistance to both rifampicin (RIF) and isoniazid with or without resistance to other anti-TB drugs [6]. Most of MDR-TB cases are due to poor adherence with TB medications, irregular use of drugs, interrupted drug supplies, physician error and accessibility of drug without prescription [7]. MDR-TB is associated with higher rates of failure and major cause of mortality in HIV co-infected patients [8]. XDR-TB defined as TB with resistance to rifampicin, isoniazid, quinolones and at least one of the three injectable second line drugs (kanamycin, capreomycin or amikacin) is increasing [9]. Drug resistance TB is difficult to treat as second line, and anti TB treatment is more toxic, less effective and costly and than first line anti-TB [8] [10].

Although TB is curable, TB burden in Nepal is high due to ignorance and less accessibility of medical care. MDR-TB cases are also increasing which further increase the risk of XDR-TB. MDR-TB is difficult to treat than first-line drugs. Hence, timely diagnosis of TB is important to control DRTB and reduce MDR-TB burden in Nepal. The objective of this study is to determine drug resistance in pulmonary tuberculosis patients and the risk factor associated with MDR-TB.

\section{Methodology}

\subsection{Study Design and Site}

The comparative cross sectional study was conducted at National Tuberculosis Center, Thimi, Bhaktapur during February 2015 to August 2015. Two hundred twenty three new or previously treated patients suspected of PTB of any age and gender visiting National Tuberculosis Center were enrolled in the study. Informed consent was taken from each patient. 


\subsection{Inclusion Criteria}

All consenting new and previously treated patients suspected of PTB of any age and gender visiting National Tuberculosis Center were included in the study.

\subsection{Exclusion Criteria}

All EPTB cases and the patients who were not able to produce $3-4 \mathrm{ml}$ of sputum sample were excluded from the study.

Two hundred twenty three early morning sputum samples were collected from patients attending OPD of National Tuberculosis Center after taking informed consent. All the samples were collected in sterile, leaf proof, wide mouth $50 \mathrm{ml}$ falcon tube [11]. The initial screening of AFB was done using fluorochrome staining method and ziehl-Neelsen staining $(\mathrm{ZN})$ and examined with a fluorescent microscope using $200 \times$ magnifications in accordance with ECDC [12]. Digestion and decontamination of sputum sample was done using Modified Petroff's method [12]. Then two to four drops of the centrifuged sediment was inoculated to each of two slopes of LJ medium. The caps of the inoculated medium tubes were loosened and placed in slanted position for 7 days at $37^{\circ} \mathrm{C}$. Thereafter, the caps of the tubes were tightened securely and further incubated in upright position at $37^{\circ} \mathrm{C}$ for 8 weeks. M. tuberculosis was identified by observing their growth rate and colony morphology (rough, tough, buff). The colonies on the $\mathrm{LJ}$ media were further confirmed by conventional biochemical tests such as susceptibility to $\mathrm{PNB}$, nitrate reductase test and catalase test at $68^{\circ} \mathrm{C}$. Drug susceptibility testing was done by proportion method. For this, a loop full of culture was taken from LJ media and suspended on $1 \mathrm{ml}$ sterile distilled water containing six $3 \mathrm{~mm}$ glass beads in a test tube. The tube was vortexed for 20 - 30 seconds using vortex mixture. After throughout mixing of the suspension, $4 \mathrm{ml}$ of sterile distilled water was added; the supernatant suspension was transferred to another sterile tube and its density /turbidity was adjusted with sterile water to that of $1 \%$ McFarland No. 1 suspension. This constitutes the 'neat suspension'. $10^{-2}$ dilution (suspension 1) was prepared by transferring 2 loops full of the neat suspension to the tube containing $2 \mathrm{ml}$ sterile distilled water and mixed well. Then, $10^{-4}$ dilution (suspension 2) was prepared by transferring 2 loops full of suspension 1 to the tube containing $2 \mathrm{ml}$ sterile distilled water and mixed well. One loop full of neat suspension was inoculated on one slant of plain LJ media containing PNB. Then, one loop full of $10^{-2}$ dilution was inoculated on one slant of each of the four drug containing LJ media and one slant of plain LJ media (Control II). Thereafter, one loop full of $10^{-4}$ dilution was inoculated on one slants of each of the four drug containing LJ media and two slants of plain LJ media (Control IV). After inoculation, the tubes were incubated at $37^{\circ} \mathrm{C}$ for 6 weeks [13].

\subsection{Statistical Analysis}

Data were analyzed using SPSS 16.0 software. The chi square test was used to compare the DST result between new and previously treated patients. The $P$ 
value of $<0.05$ was considered statically significant. The measure of association between MDR-TB and each potential risk factor was reported by odds ratio (OR) and the $95 \%$ confidence intervals (95\% CI). Initially, each potential risk factor was evaluated using univariate conditional logistic regression models. Then based on those results, a multivariate conditional logistic regression model was constructed.

\section{Results}

A total of 223 patients were enrolled in the study. Out of 223 patients, 84 (37.7\%) were male. The highest percentage $(30.9 \%)$ was seen in age group 20 - 30 years, followed by age group 31 - 40 years $(16.1 \%)$, >60 years $(14.8 \%), 51$ - 60 years $(13 \%)$, while the lowest percentage was seen in age group $<20$ years $(11.2 \%)$. The median age was 35 years (range $10-84$ years) and the mean age was 38.8 years. Similarly 125 (56.1\%) were from rural areas, 103 (46.2\%) were indigenous, 141 (63.2\%) were previously treated cases, 82 (36.8\%) were new cases, 86 (38.6\%) showed cavities on chest X-ray, 85 (38.1\%) were ZN staining positive, 105 (47.1\%) were fluorochrome staining positive, 102 (45.7\%) were culture positive, of which 39 (38.2\%) were resistance to any drug (SM + INH + RIF + EMB) and $12(11.8 \%)$ were MDR-TB cases (Table 1$)$.

Out of $102 / 223$ strains, $39(38.2 \%)$ strains were resistance to one or more drugs. Highest resistance was found in isoniazid (INH) 29 (28.4\%) either alone or in combination with other drugs, followed by rifampicin (RIF) 16 (15.7\%), streptomycin (SM) $15(14.7 \%)$ and least resistance was seen in ethambutol (EMB) 5 (4.9\%) (Table 2).

Out of (38/102) new cases, $27(71.1 \%)$ of strains were sensitive to all four drugs whereas $10(27.1 \%)$ of strains were resistant to any of the four drugs. Similarly out of (64/102) previously treated cases, $36(56.2 \%)$ were sensitive to all four drugs and remaining 28 (43.1\%) were resistant to any four drugs (Table 3 ).

In this study, it was observed that mono drug resistance was highest 18 (17.6\%) followed by double drug resistance 14 (13.7\%) and triple drug resistance $4(3.9 \%)$, while quadruple drug resistance was lowest $1(1 \%)$. The total prevalence of MDR-TB was 12 (11.7\%), of which 10 (15.6\%) were from previously treated cases and 2 (5.3\%) were from new cases (Table 2). RIF monoresistance 2 (3.1\%) was seen only in previously treated cases. Only 1 (2.3\%) relapse case exhibited quadruple drug resistance. Among previously treated cases, highest rate of MDR-TB was seen in relapse case 8 (18.2\%) followed by treatment after failure 1 (20\%) and chronic case 1 (50\%) (Table 3 and Table 4).

The initial mono, double and triple drug resistance was 6 (15.8), 3 (7.9\%) and $2(5.3 \%)$ respectively. No strain was initial quadruple drug resistance. The acquired mono, double, triple and quadruple drug resistance was 12 (18.7\%), 11 $(17.2 \%), 2(3.1 \%)$ and $1(1.6 \%)$ respectively. The initial MDR was seen in 2 $(5.3 \%)$ isolates whereas acquired MDR was seen in 10 (15.6\%) isolates (Table 5).

The univariate analysis showed female gender (cOR 8.083, 95\% CI 0.995 $64.952)$ was marginally significant $(P=0.05)$ but the other factors; age $\leq 40$ years 
Table 1. Baseline characteristics of patients.

\begin{tabular}{|c|c|c|}
\hline Characteristics & Level & $\mathrm{N}(\%)$ \\
\hline \multicolumn{3}{|l|}{ Demographic characteristics } \\
\hline \multirow[t]{6}{*}{ Age } & $<20$ & $25(11.2)$ \\
\hline & $20-30$ & $69(30.9)$ \\
\hline & $31-40$ & $36(16.1)$ \\
\hline & $41-50$ & $31(13.9)$ \\
\hline & $51-60$ & $29(13)$ \\
\hline & $<60$ & $33(14.8)$ \\
\hline \multirow[t]{2}{*}{ Gender } & Male & $84(37.7)$ \\
\hline & Female & $139(62.3)$ \\
\hline \multirow[t]{2}{*}{ Ethnicity } & Indigenous & $103(46.2)$ \\
\hline & Non Indigenous & $120(53.8)$ \\
\hline \multirow[t]{2}{*}{ Area } & Urban & $98(43.9)$ \\
\hline & Rural & $125(56.1)$ \\
\hline \multicolumn{3}{|l|}{ Clinical characteristics } \\
\hline \multirow[t]{2}{*}{ Treatment history } & New & $82(36.8)$ \\
\hline & Previously treated & $141(63.2)$ \\
\hline \multirow[t]{4}{*}{ TB symptoms } & Cough & $218(97.7)$ \\
\hline & Fever & $182(81.6)$ \\
\hline & Weight loss & $158(70.8)$ \\
\hline & Night sweat & $116(74.4)$ \\
\hline \multicolumn{3}{|l|}{ Radiological Characteristics } \\
\hline \multirow[t]{2}{*}{$\mathrm{X}$-ray findings } & Cavities & $86(38.6)$ \\
\hline & No Cavities & $137(61.4)$ \\
\hline \multicolumn{3}{|l|}{ Mycobacteriology characteristics } \\
\hline \multicolumn{3}{|l|}{ Smear results } \\
\hline \multirow[t]{2}{*}{ ZN staining } & Positive & $85(38.1)$ \\
\hline & Negative & $138(61.9)$ \\
\hline \multirow[t]{2}{*}{ Flurochrome staining } & Positive & $105(47.1)$ \\
\hline & Negative & $118(52.9)$ \\
\hline \multirow[t]{2}{*}{ Culture on LJ media } & Positive & $102(45.7)$ \\
\hline & Negative & $121(54.3)$ \\
\hline \multirow[t]{2}{*}{ Drug susceptibility Testing } & $\begin{array}{l}\text { Resistance to any one drug } \\
(\mathrm{SM}+\mathrm{INH}+\mathrm{RIF}+\mathrm{EMB})\end{array}$ & $39(38.2)$ \\
\hline & MDR-TB & $12(11.8)$ \\
\hline
\end{tabular}

Table 2. Susceptibility pattern of $M$. tuberculosis to four anti tuberculosis drugs.

\begin{tabular}{ccc}
\hline Name of drugs & Number of susceptible strains N (\%) & Number of resistant strains N (\%) \\
\hline Streptomycin & $87(85.3)$ & $15(14.7)$ \\
Isoniazid & $73(71.6)$ & $29(28.4)$ \\
Rifampicin & $86(84.3)$ & $16(15.7)$ \\
Ethambutol & $97(95.1)$ & $5(4.9)$ \\
Susceptible to all drug & $63(61.8)$ & - \\
Resistant to any drug & - & $39(37.2)$
\end{tabular}


Table 3. Drug susceptibility pattern among new and previously treated cases.

\begin{tabular}{|c|c|c|c|c|c|}
\hline Resistance pattern & Name of the drugs & $\begin{array}{l}\text { Total patients } \\
\qquad \begin{array}{c}\mathrm{N}=102 \\
\mathrm{n}(\%)\end{array}\end{array}$ & $\begin{array}{c}\text { New patients } \\
\begin{array}{c}\mathrm{N}=38 \\
\mathrm{n}(\%)\end{array}\end{array}$ & $\begin{array}{l}\text { Previously treated patients } \\
\qquad \begin{array}{c}\mathrm{N}=64 \\
\mathrm{n}(\%)\end{array}\end{array}$ & $P$ value \\
\hline Susceptible to all four drugs & $\mathrm{SM}+\mathrm{INH}+\mathrm{RIF}+\mathrm{EMB}$ & $63(61.8)$ & $27(71.1)$ & $36(56.2)$ & 0.137 \\
\hline \multirow[t]{5}{*}{ Mono drug resistance } & & $18(17.6)$ & $6(15.8)$ & $12(18.7)$ & 0.730 \\
\hline & SM & $3(2.9)$ & $1(2.6)$ & $2(3.1)$ & 0.887 \\
\hline & INH & $11(10.8)$ & $4(10.5)$ & $7(10.9)$ & 0.271 \\
\hline & RIF & $2(1.9)$ & $0(0.0)$ & $2(3.1)$ & 0.948 \\
\hline & EMB & $2(1.9)$ & $1(2.6)$ & $1(1.6)$ & 0.707 \\
\hline \multirow[t]{7}{*}{ Double drug resistance } & & $14(13.7)$ & $3(7.9)$ & $11(17.2)$ & 0.433 \\
\hline & $\mathrm{INH}+\mathrm{RIF}$ & $8(7.8)$ & $1(2.6)$ & $7(10.9)$ & 0.131 \\
\hline & $\mathrm{RIF}+\mathrm{SM}$ & $0(0.0)$ & $0(0.0)$ & $0(0.0)$ & \\
\hline & $\mathrm{SM}+\mathrm{EMB}$ & $1(1)$ & $0(0.0)$ & $1(1.6)$ & 0.439 \\
\hline & $\mathrm{EMB}+\mathrm{INH}$ & $0(0.0)$ & $0(0.0)$ & $0(0.0)$ & \\
\hline & $\mathrm{RIF}+\mathrm{EMB}$ & $0(0.0)$ & $0(0.0)$ & $0(0.0)$ & \\
\hline & $\mathrm{SM}+\mathrm{INH}$ & $5(4.9)$ & $2(5.3)$ & $3(4.7)$ & 0.896 \\
\hline \multirow[t]{5}{*}{ Triple drug resistance } & & $4(3.9)$ & $2(5.3)$ & $2(3.1)$ & 0.248 \\
\hline & $\mathrm{INH}+\mathrm{RIF}+\mathrm{SM}$ & $3(2.9)$ & $1(2.6)$ & $2(3.1)$ & 0.887 \\
\hline & $\mathrm{SM}+\mathrm{EMB}+\mathrm{INH}$ & $0(0.0)$ & $0(0.0)$ & $0(0.0)$ & \\
\hline & $\mathrm{INH}+\mathrm{RIF}+\mathrm{EMB}$ & $0(0.0)$ & $0(0.0)$ & $0(0.0)$ & \\
\hline & $\mathrm{RIF}+\mathrm{EMB}+\mathrm{SM}$ & $1(1)$ & $1(2.7)$ & $0(0.0)$ & 0.192 \\
\hline Quadruple drug resistance & $\mathrm{SM}+\mathrm{INH}+\mathrm{RIF}+\mathrm{EMB}$ & $1(1)$ & $0(0.0)$ & $1(1.6)$ & 0.386 \\
\hline MDR-TB & At least INH + RIF & $12(11.7)$ & $2(5.3)$ & $10(15.6)$ & 0.116 \\
\hline
\end{tabular}

${ }^{\star}$ New vs. previously treated; $\mathrm{INH}=$ isoniazid; RIF = rifampicin; $\mathrm{SM}=$ streptomycin; $\mathrm{EMB}=$ ethambutol; $\mathrm{MDR}-\mathrm{TB}=$ Multidrug-resistant $\mathrm{TB}$

Table 4. Drugs susceptibility pattern among previously treated cases.

\begin{tabular}{|c|c|c|c|c|c|c|c|c|}
\hline Resistancepatterns & Name of drugs & $\begin{array}{c}\text { Total patients } \\
\mathrm{N}=64 \\
\mathrm{n}(\%)\end{array}$ & $\begin{array}{c}\text { Relapse } \\
\mathrm{N}=44 \\
\mathrm{n}(\%)\end{array}$ & $\begin{array}{c}\text { TF } \\
\mathrm{N}=5 \\
\mathrm{n}(\%)\end{array}$ & $\begin{array}{c}\mathrm{F} / \mathrm{U} \\
\mathrm{N}=6 \\
\mathrm{n}(\%)\end{array}$ & $\begin{array}{l}\text { RAD } \\
\mathrm{N}=4 \\
\mathrm{n}(\%)\end{array}$ & $\begin{array}{c}\text { Chronic } \\
\mathrm{N}=2 \\
\mathrm{n}(\%)\end{array}$ & $\begin{array}{l}\text { Others } \\
\mathrm{N}=3 \\
\mathrm{n}(\%)\end{array}$ \\
\hline \multirow[t]{3}{*}{ Susceptible to all four drugs } & $\mathrm{SM}+\mathrm{INH}+\mathrm{RIF}+\mathrm{EMB}$ & $36(56.2)$ & $24(54.5)$ & $3(60)$ & $4(66.7)$ & $1(25)$ & $1(50)$ & $3(100)$ \\
\hline & & $12(18.7)$ & $8(18.2)$ & $0(0.0)$ & $2(33.4)$ & $2(50)$ & $0(0.0)$ & $0(0.0)$ \\
\hline & SM & $2(3.1)$ & $0(0.0)$ & $0(0.0)$ & $1(16.7)$ & $1(25)$ & $0(0.0)$ & $0(0.0)$ \\
\hline \multirow[t]{6}{*}{ Mono drug resistance } & INH & $7(10.9)$ & $6(13.6)$ & $0(0.0)$ & $0(0.0)$ & $1(25)$ & $0(0.0)$ & $0(0.0)$ \\
\hline & RIF & $2(3.1)$ & $1(2.3)$ & $0(0.0)$ & $1(16.7)$ & $0(0.0)$ & $0(0.0)$ & $0(0.0)$ \\
\hline & EMB & $1(1.6)$ & $1(2.3)$ & $0(0.0)$ & $0(0.0)$ & $0(0.0)$ & $0(0.0)$ & $0(0.0)$ \\
\hline & & $11(17.2)$ & $8(18.2)$ & $2(40)$ & $0(0.0)$ & $1(25)$ & $0(0.0)$ & $0(0.0)$ \\
\hline & $\mathrm{INH}+\mathrm{RIF}$ & $7(10.9)$ & $6(13.6)$ & $1(20)$ & $0(0.0)$ & $0(0.0)$ & $0(0.0)$ & $0(0.0)$ \\
\hline & $\mathrm{RIF}+\mathrm{SM}$ & $0(0.0)$ & $0(0.0)$ & $0(0.0)$ & $0(0.0)$ & $0(0.0)$ & $0(0.0)$ & $0(0.0)$ \\
\hline \multirow[t]{4}{*}{ Double drug resistance } & $\mathrm{SM}+\mathrm{EMB}$ & $1(1.6)$ & $1(2.3)$ & $0(0.0)$ & $0(0.0)$ & $0(0.0)$ & $0(0.0)$ & $0(0.0)$ \\
\hline & $\mathrm{EMB}+\mathrm{INH}$ & $0(0.0)$ & $0(0.0)$ & $0(0.0)$ & $0(0.0)$ & $0(0.0)$ & $0(0.0)$ & $0(0.0)$ \\
\hline & $\mathrm{RIF}+\mathrm{EMB}$ & $0(0.0)$ & $0(0.0)$ & $0(0.0)$ & $0(0.0)$ & $0(0.0)$ & $0(0.0)$ & $0(0.0)$ \\
\hline & $\mathrm{SM}+\mathrm{INH}$ & $3(4.7)$ & $1(2.3)$ & $1(20)$ & $0(0.0)$ & $1(25)$ & $0(0.0)$ & $0(0.0)$ \\
\hline
\end{tabular}




\begin{tabular}{ccccccccc}
\hline & & & & & & & & \\
& & $2(3.1)$ & $1(2.3)$ & $0(0.0)$ & $0(0.0)$ & $0(0.0)$ & $1(50)$ & $0(0.0)$ \\
Triple drug resistance & INH + RIF + SM & $2(3.1)$ & $1(2.3)$ & $0(0.0)$ & $0(0.0)$ & $0(0.0)$ & $1(50)$ & $0(0.0)$ \\
& SM + EMB + INH & $0(0.0)$ & $0(0.0)$ & $0(0.0)$ & $0(0.0)$ & $0(0.0)$ & $0(0.0)$ & $0(0.0)$ \\
& INH + RIF + EMB & $0(0.0)$ & $0(0.0)$ & $0(0.0)$ & $0(0.0)$ & $0(0.0)$ & $0(0.0)$ & $0(0.0)$ \\
& RIF + EMB + SM & $0(0.0)$ & $0(0.0)$ & $0(0.0)$ & $0(0.0)$ & $0(0.0)$ & $0(0.0)$ & $0(0.0)$ \\
Quadruple drug resistance & SM + INH + RIF + EMB & $1(1.6)$ & $1(2.3)$ & $0(0.0)$ & $0(0.0)$ & $0(0.0)$ & $0(0.0)$ & $0(0.0)$ \\
MDR-TB & At least INH + RIF & $10(15.6)$ & $8(18.1)$ & $1(20)$ & $0(0.0)$ & $0(0.0)$ & $1(50)$ & $0(0.0)$ \\
\hline
\end{tabular}

$\mathrm{TF}=$ Treatment after failure; $\mathrm{F} / \mathrm{U}=$ Follow up; RAD = Return after default; $\mathrm{INH}=$ isoniazid; RIF = rifampicin; $\mathrm{SM}=$ streptomycin; $\mathrm{EMB}=$ ethambutol; MDR-TB $=$ Multidrug-resistant TB.

Table 5. Initial and acquired anti-TB drug resistance.

\begin{tabular}{cccccc}
\hline Drug resistance & Mono n (\%) & Double n (\%) & Triple n (\%) & Quadruple n (\%) & MDR n (\%) \\
\hline Initial drug resistance $(\mathbf{N}=\mathbf{3 8})$ & $6(15.8)$ & $3(7.9)$ & $2(5.3)$ & 0 & $2(5.3)$ \\
Acquired drug resistance $(\mathrm{N}=\mathbf{6 4})$ & $12(18.7)$ & $11(17.2)$ & $2(3.1)$ & $1(1.6)$ & $10(15.6)$ \\
\hline
\end{tabular}

(cOR 1.308, 95\% CI 0.392 - 4.368), previously treated TB (cOR 0.300, 95\% CI 0.062 - 1.450), urban area (cOR 1.051, 95\% CI 0.293 - 3.766) and chest X-Ray (cOR $0.583,95 \%$ CI 0.119 - 2.858) were not significantly associated with MDR-T $\mathrm{B}(\mathrm{p}>0.05)$. The final multivariable logistic regression model identified female gender (aOR 9.237, 95\% CI 1.032 - 82.705) was associated with MDR-TB whereas the other factors; age $\leq 40$ years (aOR 0.649 , 95\%CI 0.166 - 2.532), previously treated TB ( aOR 0.262 , 95\% CI 0.050 - 1.366), Indigenous (aOR 0.665, $95 \%$ CI 0.175 - 2.524), urban area (aOR 1.08, 95\% CI 0.276 - 4.198) and chest $\mathrm{X}$-Ray (aOR $0.633,95 \% \mathrm{CI} 0.118$ - 1.037) were not associated with MDR-TB $(P>$ 0.05) (Table 6).

\section{Discussion}

In the current study, the prevalence of resistance to one or more first line drug was $37.2 \%$. The reasons for high resistance rate might be due to delay in treatment, irregular supply of drugs and unavailability of drugs. The lower rate of resistance to one or more first line anti-TB drug was reported from Jimma (18.4\%) [14] and Arsi (18.2\%) [15]. A comparable rate of resistance has been reported from similar surveys from Uganda (28.6\%) [16] but the higher rate of resistance (56\%) to one or more first line drug was also reported from Calabar, Nigeria [17]. The similar previous study reported drug resistance to one or more anti-TB drugs in different African countries was within the range of $28.6 \%$ - 56\% [18]. The other studies in Asia reported the proportion of resistance ranged from $18.7 \%-30.2 \%$ [19] [20] [21].

In this study highest rate of monoresistance was associated with INH (10.8\%). The high rate of resistance to INH in this study might be due to poor management or the common use of the drug in the national TB control programme for longer time because of its accessibility. Wiwing et al (2015) stated that the pro- 
Table 6. Factors associated with MDR-TB.

\begin{tabular}{|c|c|c|c|c|c|c|c|c|}
\hline \multirow{2}{*}{ Variable } & \multirow{2}{*}{$\begin{array}{c}\text { MDR-TB } \\
\mathrm{N}=12 \\
\mathrm{n}(\%)\end{array}$} & \multirow{2}{*}{$\begin{array}{c}\text { Non MDR-TB } \\
\begin{array}{c}\mathrm{N}=90 \\
\mathrm{n}(\%)\end{array}\end{array}$} & \multicolumn{3}{|c|}{ Univariate } & \multicolumn{3}{|c|}{ Multivariate } \\
\hline & & & $\mathrm{cOR}$ & $95 \%$ CI & $P$-value & $\mathrm{aOR}$ & $95 \% \mathrm{CI}$ & $P$-value \\
\hline \multicolumn{9}{|l|}{ Sex } \\
\hline $\begin{array}{l}\text { Female } \\
\text { Male }^{\star}\end{array}$ & $\begin{array}{c}1(8.3) \\
11(91.7)\end{array}$ & $\begin{array}{l}38(42.2) \\
52(57.8)\end{array}$ & 8.083 & $0.995-64.952$ & 0.05 & 9.237 & $1.032-82.705$ & 0.05 \\
\hline \multicolumn{9}{|l|}{ Age } \\
\hline $\begin{array}{c}\leq 40 \text { years } \\
\geq 40 \text { years }^{\star}\end{array}$ & $\begin{array}{l}6(50) \\
6(50)\end{array}$ & $\begin{array}{l}51(56.7) \\
39(43.3)\end{array}$ & 1.308 & $0.392-4.368$ & 0.66 & 0.649 & $0.166-2.532$ & 0.53 \\
\hline $\begin{array}{l}\text { Treatment history } \\
\text { Previously treated TB } \\
\text { New case }\end{array}$ & $\begin{array}{c}10(83.3) \\
2(16.7)\end{array}$ & $\begin{array}{l}54(60) \\
36(40)\end{array}$ & 0.300 & $0.062-1.450$ & 0.13 & 0.262 & $0.050-1.366$ & 0.11 \\
\hline \multicolumn{9}{|l|}{ Ethnicity } \\
\hline $\begin{array}{c}\text { Indigenous } \\
\text { Non-Indigenous }\end{array}$ & $\begin{array}{l}6(50) \\
6(50)\end{array}$ & $\begin{array}{l}42(46.7) \\
48(53.3)\end{array}$ & 1.143 & $0.343-3.813$ & 0.94 & 0.665 & $0.175-2.524$ & 0.55 \\
\hline \multicolumn{9}{|l|}{ Area } \\
\hline $\begin{array}{l}\text { Urban } \\
\text { Rural }\end{array}$ & $\begin{array}{l}4(33.3) \\
8(66.7)\end{array}$ & $\begin{array}{l}31(34.4) \\
59(65.5)\end{array}$ & 1.051 & $0.293-3.766$ & 0.939 & 1.089 & $0.276-4.198$ & 0.904 \\
\hline \multicolumn{9}{|l|}{ Chest X-Ray } \\
\hline $\begin{array}{c}\text { Cavitation } \\
\text { Non-Cavitation* }\end{array}$ & $\begin{array}{l}10(83.3) \\
2(16.7)\end{array}$ & $\begin{array}{l}67(74.4) \\
23(25.6)\end{array}$ & 0.583 & $0.119-2.858$ & 0.506 & 0.633 & $0.118-1.037$ & 0.593 \\
\hline
\end{tabular}

$\mathrm{cOR}$ = crude odds ratio; $\mathrm{aOR}=$ adjusted odds ratio, adjusted for sex, age, treatment history, ethnicity, area and chest X-ray; ${ }^{*}$ reference category. Values in boldface indicate a significant $(P<0.05)$ difference between Non MDR and MDR-TB.

portion of INH resistance exceeding $10 \%$ predicts the development of MDR-TB [21] and Ndungu's et al (2012) stated that most MDR-TB cases develop from initial INH monoresistance [22], from these two surveys, it is reasonable to conclude that the probability of developing MDR-TB in study population in future is high. The studies from Ethiopia reported the proportion of resistance to INH was in range of $1.9 \%-21.4 \%$ [18]. INH monoresistance in this study is lower than reported from Sri Lanka (12.2\%) [23], Mozambique (14.9\%) [24] and Kenya (12.9\%) [22].

In the current study RIF monoresistance was found only in $1.9 \%$ of the study population whereas monoresistance to EMB and SM was $1.9 \%$ and $2.9 \%$ respectively. The probable reason for RIF resistance might be due to broad use of RIF for the treatment of other bacterial infections. The reason for lower proportion of RIF resistance might be recent introduction of the drug as compared to INH and SM. The studies from Ethiopia reported the proportion of resistance to RIF was in range of $0 \%-1.9 \%$ [15]. Similarly, the higher rate (5.9\%) of RIF monoresistance was reported from Northeastern China [25]. In the similar study conducted in Nepal, monoresistance to INH, RIF, EMB and SM was 9.31\%, 3.1\%, $0.62 \%$ and $19.25 \%$ respectively [26]. The similar past study conducted at Pakis$\tan$ showed very high rate of resistance to INH (51.22\%), RIF (15.4\%), EMB 
(13.33\%) and SM (3.85\%) [27].

The prevalence of MDR-TB in this study was $11.7 \%$, of which $2(5.3 \%)$ were initial MDR-TB and $10(15.6 \%)$ were acquired MDR-TB. The high rate of MDR-TB might be due to poor patient management, non-adherence to the prescribed regimen, irregular supply of drugs, poor quality of drugs and poor national TB control programme. The study from Ethiopia showed lower rate of MDR-TB ranged from 1.1\% - 7.7\% [18]. The similar past study in Nepal revealed comparatively higher rate of acquired MDR-TB (19.25\%) and lower rate of initial MDR-TB (2.63\%) [26]. However, another study conducted at eastern part of Nepal showed the rate of acquired MDR-TB was $5.51 \%$ and initial MDR-TB was $4.6 \%$ which is similar to the current study [28]. According to Lukoye et al (2013), if the prevalence of initial MDR-TB exceeds 3\%, it was considered as high MDR-TB burden [29]. As initial MDR-TB exceeded 3\% in this study, it is reasonable to conclude that MDR-TB burden is high in the study population. Hence, it is urgent to strengthen capacity to perform DST in order to prevent transmission of MDR-TB in the community. MDR-TB patients are at high risk of XDR-TB which is expensive and require long time period to treat. Besides, second line drugs are less effective, display cross resistance and high toxicity profiles. So, in order to combat those issues related to XDR-TB, MDR-TB should be controlled first. This could be overcome by more surveillance and immediate therapeutic interventions and effective implementation of DOTS strategy.

In this study double drug resistant (13.7\%) was also high. The most common double drug resistance pattern in this study was resistance to INH + RIF (7.8\%) and SM + RIF (4.9\%). On the other hand, triple drug resistance (3.9\%) was low in this study. The common triple drug resistance pattern in this study was INH + RIF + SM (2.9\%). Quadruple drug resistance was rare in this study. Only one relapse case exhibited quadruple drug resistance pattern. In the study conducted by Nagaraja et al (2011), showed rate of resistance pattern of SM + INH + RIF + $\mathrm{EMB}, \mathrm{SM}+\mathrm{INH}+\mathrm{RIF}, \mathrm{INH}+\mathrm{RIF}$ and INH + RIF + EMB was $65.2 \%, 17.4 \%$, $8.9 \%$ and $8.5 \%$ respectively [10].

The multivariate analysis in this study, after adjusting sex with age, ethnicity, area and chest X-ray showed that females are about 9 times more likely to be at the risk of developing MDR-TB than males (95\% CI: 1.032 - 82.705), $P=0.05$. The reasons for the association between female and MDR-TB might be related to the fact that women spend more time caring their family members with MDRTB both in households and healthcare settings. The another reason might be low priority of women health in the family as compared to men which act as barrier in accessing health care causing delay in TB diagnosis. It could be due to poor nutritional status of women because women compromise their own nutrition in order to ensure other family members are adequately nourished. The similar survey conducted at Northeastern China showed females are more likely to suffer from TB than males [25] but another similar study showed male gender was at the higher risk of MDR-TB [30]. Some studies have also reported previous treatment and age group 24 - 54 years to be risk factors of MDR-TB [25] [30]. 
However, this study did not show any association of age $(P=0.533)$ and TB cases $(P=0.112)$ with MDR-TB.

\section{Limitation of the Study}

One of the limitations was selection bias; not including all public health facilitates (hospitals and health centers) due to resource constraints. Another limitation was although a detailed history was obtained from the patients, assignment of the patient to new or retreatment categories was based upon the information given by patients and may not have been accurate. Therefore, we cannot exclude the possibility of misclassification. Besides, as this study was conducted among service seekers at NTC, these observations may not be generalized to the entire country. However, the results remain important since the increasing level of drug resistance among Mycobacterium tuberculosis isolates in study population was alarming.

\section{Conclusion}

The overall resistance to first line anti-TB drugs was high. The drug resistance was high in previously treated TB cases as compared to new TB cases. The highest mono drug resistance was detected against INH. RIF mono resistant was rare and was seen only in previously treated cases. The overall prevalence of MDRTB was high. The acquired MDR-TB was higher than initial MDR-TB and female was found to be associated with MDR-TB. Hence, early diagnosis of TB is crucial to combat the threat of MDR-TB. It could be achieved by revised DOTS program though prompt case detection as well as routine and quality assured DST.

\section{Acknowledgements}

The authors acknowledge Dr. Bikash Lamichhane, Director, National Tuberculoss Center Thimi, Bhaktapur and all the staffs of National Tuberculosis centre and SAARC TB and HIV/AIDS centre for their constant support and time. The authors also want to Mr. Meghraj Banjara for his valuable time.

\section{References}

[1] Moamcp, D.A. (2007) Evaluation of Direct Detection of Mycobacterium tuberculosis Rifampin. Journal of Clinical Microbiology, 2123-2125.

[2] Fauci, A.S., NIAID Tuberculosis Working Group (2008) Multidrug-Resistant and Extensively Drug-Resistant Tuberculosis: The National Institute of Allergy and Infectious Diseases Research Agenda and Recommendations for Priority Research. The Journal of Infectious Disease, 1493-1498.

[3] National Tuberculosis Programme (2014) National Tuberculosis Programme Annual Report 2014. Annual Report. National Tuberculosis Programme, Department of Health Sciences, Thimi, Bhaktapur.

[4] Department of Health Services (2014) Annual Report Department of Health Services 2013/2014. Teku, Kathmandu.

[5] Patra, S.K., Jain, A., Sherwal, B.L. and Khanna, A. (2010) Rapid Detection of Muta- 
tion in RRDR of rpo B Gene. Indian Journal of Clinical Biochemistry, 315-318.

[6] Ormerod, L.P. (2005) Multidrug-Resistant Tuberculosis (MDR-TB): Epidemiology, Prevention and Treatment. British Medical Bulletin, 17-24. https://doi.org/10.1093/bmb/ldh047

[7] Range, N., Friis, H., Mfaume, S., Magnussen, P., Chanualucha, J., Kilale, A., Mugomela, A. and Andersen, A.B. (2012) Anti-Tuberculosis Drug Resistance Pattern among Pulmonary Tuberculosis Patients with or without HIV infection in Mwanza, Tanzania. Tanzania Journal of Health Research, 1-6.

[8] Bang, D. (2010) The Management of Tuberculosis: Epidemiology, Resistance and Monitoring. Dansh Medical Bulletin, 4213.

[9] Marahatta, S. (2010) Multi-Drug Resistant Tuberculosis Burden and Risk Factors: An Update. Kathmandu University Medical Journal, 8, 116-125. https://doi.org/10.3126/kumj.v8i1.3234

[10] Sbammpsc, N.C. (2012) Pattern of Drug-Resistance and Treatment Outcome in Multidrug-Resistant Pulmonary Tuberculosis. Indian Journal of Chest Diseases \& Allied Sciences, 23-26.

[11] SAARC TB and HIV/AIDS Centre (2011) SAARC Training Modules for AFB Smear Microscopy and Quality Assurance in AFB Smear Microscopy. Trainer's Manual. SAARC TB and HIV/AIDS Centre, SAARC TB and HIV/AIDS Centre, Thimi, Bhaktapur.

[12] European Center for Disease Prevention and Control (2011) Mastering the Basics of TB Control. ECDC Technical Report, European Center for Disease Prevention and Control, European Center for Disease Prevention and Control.

[13] Programme RNTC (2009) Revised National TB Control Programme Training Manual for Mycobacterium tuberculosis Culture \& Drug Susceptibility Testing. Training Manual, Indian Council of Medical Research) and National Tuberculosis Institute, Central TB Division, Nirman Bhawan, New Delhi.

[14] Abebe, G., et al. (2012) Relatively Low Primary Drug Resistant Tuberculosis in Southwestern Ethiopia. BMC Research Notes, 5, 225. https://doi.org/10.1186/1756-0500-5-225

[15] Gebeyehu, M., Lemma, E. and Eyob, G. (2001) Prevalence of Drug Resistant Tuberculosis in Arsi Zone, Ethiopia. Ethiopian Journal of Health Development, 15, 11 16. https://doi.org/10.4314/ejhd.v15i1.9891

[16] Sanchez-Padilla, E., et al. (2013) Multidrug- and Isoniazid-Resistant Tuberculosis in Three High HIV. The International Journal of Tuberculosis and Lung Disease, 17, 1036-1042. https://doi.org/10.5588/ijtld.12.0842

[17] Out, A., et al. (2013) Drug Resistance among Pulmonary Tuberculosis. Pulmonary Medicine, 2013, Article ID: 235190.

[18] Seyoum, B., Demissie, M., Worku, A., Bekele, S. and Aseffa, A. (2014) Prevalence and Drug Resistance Patterns of Mycobacterium tuberculosis among New Smear Positive Pulmonary Tuberculosis Patients in Eastern Ethiopia. Tuberculosis Research and Treatment, 2014, Article: ID 753492. https://doi.org/10.1155/2014/753492

[19] Lee, J.H. and Chang, J.H. (2001) Drug-Resistant Tuberculosis in a Tertiary Referral Teaching Hospital of Korea. The Korean Journal of Internal Medicine, 16, 173-179. https://doi.org/10.3904/kjim.2001.16.3.173

[20] Zhao, Y., et al. (2012) National Survey of Drug-Resistant Tuberculosis in China. The New England Journal of Medicine, 366, 2161-2170.

https://doi.org/10.1056/NEJMoa1108789 
[21] Cucunawangsih, Wiwing, V., Widysanto, A. and Lugito, N.P.H. (2015) Mycobacterium tuberculosis Resistance Pattern against First-Line Drugs in Patients from Urban Area. International Journal of Mycobacteriology, 4, 302-305.

https://doi.org/10.1016/j.ijmyco.2015.08.002

[22] Ndung'u, P.W., et al. (2012) Resistance Patterns of Mycobacterium tuberculosis Isolates from Pulmonary Tuberculosis Patients in Nairobi. The Journal of Infection in Developing Countries, 61, 33-39.

[23] Magana-Arachchi, D.N., Perera, A.J., Senaratne, V. and Chandrasekharan, N.V. (2010) Patterns of Drug Resistance and RFLP Analysis of Mycobacterium tuberculosis Strains Isolated from Recurrent Tuberculosis Patients in Sri Lanka. Southeast Asian Journal of Tropical Medicine and Public Health, 41, 583-589.

[24] Nunes, E.A., et al. (2008) Mycobacterium tuberculosis and Non-Tuberculous Mycobacterium Isolates among Patients with Recent HIV Infection in Mozambique. Jornal Brasileiro de Pneumologia, 34, 822-828. https://doi.org/10.1590/S1806-37132008001000011

[25] Liu, Q., et al. (2013) Rates and Risk Factors for Drug Resistance Tuberculosis in Northeastern China. BMC Public Health, 13, 1171. https://doi.org/10.1186/1471-2458-13-1171

[26] Rijal, K.R., Ghimire, P., Rijal, B. and Bam, D.S. (2005) The Pattern of Anti-Tuberculosis Drug Resistance in Pulmonary Tuberculosis Patients. Journal of Institute of Medicine, 27, 26-28.

[27] Khoharo, H.K. and Shaikh, I.A. (2011) Drug Resistance Patterns in Pulmonary Tuberculosis. Journal of the Pakistan Medical Association, 61, 229-232.

[28] Pradhan, P., et al. (2014) Drug Resistance Pattern of Mycobacteria Isolated from Smear Positive Cases of Pulmonary Tuberculosis in Eastern Part of Nepal. Journal of General Practice Emergency Medical Nepal, 8-11.

[29] Lukoye, D., et al. (2011) Rates of Anti-Tuberculosis Drug Resistance in KampalaUganda Are Low and Not Associated with HIV Infection. PLOS ONE, 6, e16130. https://doi.org/10.1371/journal.pone.0016130

[30] Johnston, J.C., Shahidi, N.C., Sadatsafavi, M. and Fitzgerald, J.M. (2009) Treatment Outcomes of Multidrug-Resistant Tuberculosis: A Systematic Review and MetaAnalysis. PLoS ONE, 4, e6914. https://doi.org/10.1371/journal.pone.0006914

Submit or recommend next manuscript to SCIRP and we will provide best service for you:

Accepting pre-submission inquiries through Email, Facebook, LinkedIn, Twitter, etc. A wide selection of journals (inclusive of 9 subjects, more than 200 journals)

Providing 24-hour high-quality service

User-friendly online submission system

Fair and swift peer-review system

Efficient typesetting and proofreading procedure

Display of the result of downloads and visits, as well as the number of cited articles

Maximum dissemination of your research work

Submit your manuscript at: http://papersubmission.scirp.org/

Or contact jtr@scirp.org 